\title{
KELAYAKAN FINANSIAL DAN PENDAPATAN USAHA BUDIDAYA IKAN PATIN STUDI KASUS DI CV XYZ KECAMATAN BUMI RATU NUBAN KABUPATEN LAMPUNG TENGAH
}

\author{
(Financial and Income Feasibility of Patin Fish Culture: Case Study in CV XYZ Central Lampung District) \\ Vivi Ayu Yuliana, Fembriarti Erry Prasmatiwi, Muhammad Irfan Affandi \\ Jurusan Agribisnis, Fakultas Pertanian, Universitas Lampung. Jl. Sumantri Brojonegoro No. 1 \\ Bandar Lampung, 35145, e-mail: fembriarti.erry@fp.unila.ac.id
}

\begin{abstract}
Patin fish culture requires a large amount in terms of cost in its implementation. This study aims to analyze business performance financial, production, and marketing aspects. The research method used is a case study in CV XYZ in Central Lampung District conducted in May-June 2019. Measurement of business performance from a financial aspect uses NPV, IRR, Net B / C, Gross B / C, and Payback Period with 12 percent interest rate. Measurement of business performance from the aspect of production uses the calculation of productivity and income during season one and season two. The study concludes that the patin fish culture business per 1,000 $\mathrm{m}^{2}$ was profitable to run, seen from the IRR value at 13.06 percent, NPV at 22,671,483.98, Net B/C at 1.05, Gross B/C at 1.01, and Payback Period at 7.67. The patin fish culture business from the aspect of production has been profitable based on the productivity obtained, namely per pond of $1.000 \mathrm{~kg}$ in season one and $750 \mathrm{~kg}$ in season two, per hectare at 50,000 kg in season one and 37,500 $\mathrm{kg}$ in season two.
\end{abstract}

Key words: financial, income, patin fish

\section{PENDAHULUAN}

Perikanan merupakan sektor ekonomi yang penting kedudukannya di Indonesia. Data Produk Domestik Bruto (PDB) Indonesia menurut sektor usaha pada tahun 2014 menunjukkan bahwa sektor perikanan menjadi sektor ketiga yang mempengaruhi laju pertumbuhan ekonomi. Sektor pertanian, peternakan, kehutanan, dan perikanan menyumbang 12,53 persen dari total PDB tahun 2014. Melihat pentingnya sektor perikanan bagi kelangsungan hidup negara, maka diperlukan upaya nyata untuk mengembangkan dan memajukan sektor perikanan secara berkelanjutan (Badan Pusat Statistik, 2014)

Instruksi Presiden Nomor 7 tahun 2016 tentang Percepatan Pembangunan Industri Perikanan Nasional telah mengamanatkan kepada 25 Kementerian dan Lembaga terkait untuk melakukan langkah-langkah strategis yang diperlukan dalam mendukung upaya percepatan pembangunan industri perikanan nasional. Salah satu langkah yang diamanatkan dalam instruksi Presiden tersebut yaitu peningkatan produksi perikanan tangkap, budidaya, dan pengolahan hasil perikanan (Kementerian Kesehatan Republik Indonesia, 2018)
Provinsi Lampung merupakan salah satu sentra produksi perikanan di Indonesia. Sektor perikanan di Provinsi Lampung meliputi perikanan tangkap dan perikanan budidaya. Produksi perikanan tangkap pada tahun 2017 mengalami penurunan dibandingkan dengan tahun 2016 yaitu sebesar 64.583 ton. Produksi perikanan budidaya pada tahun 2017 yaitu sebesar 155.716,84 ton. Produksi perikanan terbesar di Provinsi Lampung adalah perikanan budidaya yang berasal dari kolam yaitu $84.461,55$ ton. (BPS Provinsi Lampung, 2018).

Di Provinsi Lampung, Kabupaten Lampung Tengah merupakan daerah penghasil perikanan kolam terbesar dengan produksi yaitu 35.341 ton pada tahun 2017. Di Kabupaten Lampung Tengah terdapat beberapa macam komoditas perikanan yang di budidayakan seperti ikan lele, ikan mas, ikan nila, ikan patin, dan sebagainya. Produksi ikan terbesar di Kabupaten Lampung Tengah adalah ikan patin dengan produksi 11.507 ton pada tahun 2017. Di Kabupaten Lampung Tengah terdapat perusahaan yang mengusahakan budidaya ikan patin yaitu CV XYZ.

CV XYZ merupakan perusahaan komanditer yang mengusahakan budidaya ikan patin. Luas lahan yang dimiliki yaitu 0,5 ha dan memiliki 23 kolam budidaya. Jenis usaha yang di budidayakan adalah 
pembesaran ikan patin. Budidaya ikan patin berlangsung selama 6-8 bulan hingga ukuran ikan patin siap dipanen dan dipasarkan. CV XYZ telah melakukan usaha pembesaran ikan patin sejak tahun 2012. Ikan patin yang dijual oleh CV XYZ ini berupa ikan patin segar.

Permasalahan yang ada di CV XYZ ini adalah terkait permodalan yang mengakibatkan perusahaan belum dapat meningkatkan produksi. Budidaya ikan patin memerlukan biaya investasi yang cukup besar sehingga masa pengembalian investasi lama. Biaya investasi dalam usaha budidaya ikan patin ini cukup besar sehingga diperlukan pengukuran kelayakan usaha secara finansial.

Pengukuran kelayakan usaha dari aspek finansial dapat diketahui berdasarkan beberapa penilaian kriteria investasi seperti NPV, IRR, Net B/C, Gross B/C, Payback Period, dan analisis sensitivitas untuk mengukur sejauh mana perusahaan mampu mempertahankan usahanya apabila terjadi perubahan harga jual dan perubahan produksi.

Penggunaan benih, pakan dan sarana produksi lain memerlukan banyak biaya yang harus dikeluarkan. Masing-masing sarana produksi tersebut harganya berfluktuasi setiap tahunnya sehingga biaya yang dikeluarkan semakin besar. Pengukuran produktivitas dan pendapatan diperlukan untuk mengetahui apakah usaha ini sudah efektif dalam menggunakan sumber daya yang ada dan menguntungkan untuk dijalankan. Dengan demikian penelitian ini bertujuan untuk menghitung kelayakan finansial dan pendapatan usaha budidaya ikan patin di CV XYZ.

\section{METODE PENELITIAN}

Penelitian ini dilakukan dengan menggunakan metode studi kasus di CV XYZ karena perusahaan tersebut memiliki jumlah kolam budidaya yang cukup banyak. CV XYZ terletak di Kecamatan Bumi Ratu Nuban Kabupaten Lampung Tengah. Data yang dikumpulkan dalam penelitian ini yaitu data primer dan data sekunder. Data primer diperoleh melalui kegiatan wawancara secara langsung menggunakan kuesioner. Data sekunder diperoleh melalui studi pustaka, lembaga/instansi terkait seperti Badan Pusat Statistik, dan Kementerian Kelautan dan Perikanan.

Metode analisis data yang akan digunakan dalam penelitian ini adalah analisis deskriptif kuantitatif yang digunakan untuk menganalisis pendapatan dan kelayakan finansial dengan kriteria NPV, IRR, Net B/C, Gross B/C, Payback Period, dan analisis sensitivitas. Penentuan umur proyek mengacu pada umur ekonomis kolam budidaya yaitu 10 tahun. CV XYZ dalam kegiatan usahanya memperoleh modal pinjaman dari Rabo bank dengan biaya bunga sebesar 12 persen per tahun.

NPV merupakan selisih antara Present Value dari benefit dan Present Value dari biaya. Menurut Pasaribu (2012) secara matematis dirumuskan :

$\mathrm{NPV}=\sum_{\mathrm{t}=\mathrm{n}}^{\mathrm{i}=0} \frac{\mathrm{B}_{\mathrm{t}}-\mathrm{C}_{\mathrm{t}}}{(1+\mathrm{i})^{\mathrm{t}}}$

Keterangan :

$\mathrm{B}_{\mathrm{t}} \quad=$ Penerimaan pada tahun ke- $\mathrm{t}$

$\mathrm{C}_{\mathrm{t}}=$ Cost pada tahun ke- $\mathrm{t}$

$\mathrm{N}=$ Waktu umur proyek (10 tahun)

$\mathrm{I} \quad=$ Tingkat suku bunga (12\%/tahun)

Net B/C adalah perbandingan antara jumlah NPV positif dengan jumlah NPV negatif. Menurut Pasaribu (2012) secara matematis dirumuskan :

Net $\mathrm{B} / \mathrm{C}=\frac{\sum_{\mathrm{t}=0}^{\mathrm{t}=0 \mathrm{Bt}-\mathrm{Cl}}(1+\mathrm{C})^{\mathrm{t}}}{\sum_{\mathrm{t}=0}^{\mathrm{t}=\mathrm{C}(\mathrm{Ct}-\mathrm{B}}(1+\mathrm{i})^{\mathrm{t}}}$

Gross B/C adalah rasio antara jumlah Present Value Benefit (PVB) dengan Present Value Cost (PVC). Menurut Pasaribu (2012) secara matematis dirumuskan sebagai berikut :

Gross $\mathrm{B} / \mathrm{C}=\frac{\sum_{\mathrm{t}=0}^{\mathrm{t}=\mathrm{n}}\left(\mathrm{B}_{\mathrm{t}}\right)(\mathrm{DF})}{\sum_{\mathrm{t}=0}^{\mathrm{t}=\mathrm{n}}\left(\mathrm{C}_{\mathrm{t}}\right)(\mathrm{DF})}$

IRR ialah untuk mengetahui sebagai alat ukur kemampuan proyek dalam mengembalikan bunga pinjaman dari lembaga internal keuangan yang membiayai proyek tersebut. Menurut Pasaribu (2012) secara matematis dirumuskan :

$\mathrm{IRR}=\mathrm{i}_{1}+\frac{\mathrm{NPV}_{1}}{\mathrm{NPV}_{1}-\mathrm{NPV}_{2}}\left(\mathrm{i}_{2}-\mathrm{i}_{1}\right)$

Keterangan :

$\mathrm{NPV}_{1}=\mathrm{NPV}$ positif

$\mathrm{NPV}_{2}=\mathrm{NPV}$ negatif

$\mathrm{I}_{1}=$ Discount/Compound factor pertama dimana diperoleh NPV positif

$\mathrm{I}_{2}=$ Discount/Compound factor kedua dimana diperoleh NPV negatif

Payback Period adalah jangka waktu pengembalian modal investasi yang akan dibayarkan melalui keuntungan yang diperoleh 
proyek tersebut. Menurut Pasaribu (2012) secara matematis dirumuskan :

$\mathrm{PP}=\mathrm{n}+\frac{\mathrm{a}-\mathrm{b}}{\mathrm{c}-\mathrm{b}} \times 1$ tahun

Keterangan :

$\mathrm{n}=$ Tahun terakhir dimana arus kas masih belum bisa menutupi initial investment

$\mathrm{a}=$ Jumlah investasi

$\mathrm{b}=$ Jumlah kumulatif arus kas pada tahun ke-n

$\mathrm{c}=$ Jumlah kumulatif arus kas pada tahun ke$\mathrm{n}+1$

Pengukuran sensitivitas bertujuan untuk melihat kepekaan dari analisis NPV, IRR, Gross B/C, Net B/C, dan Payback period terhadap perubahan harga jual, biaya produksi, dan produksi ikan patin.

Laju Kepekaan $=\frac{\left|\frac{\mathrm{X}_{\mathrm{i}}-\mathrm{X}_{0}}{\mathrm{X}}\right| \times 100 \%}{\left|\frac{\mathrm{Y}_{\mathrm{i}} \mathrm{Y}_{0}}{\mathrm{Y}}\right| \times 100 \%}$

Keterangan :

$\mathrm{X}_{1}=$ Gross $\mathrm{B} / \mathrm{C}$, Net B/C, NPV, IRR, PP setelah perubahan

$\mathrm{X}_{0}=$ Gross B/C, Net B/C, NPV, IRR, PP sebelum perubahan

$\mathrm{X}=$ Rata-rata perubahan Gross $\mathrm{B} / \mathrm{C}$, Net $\mathrm{B} / \mathrm{C}$, NPV, IRR, PP

$\mathrm{Y}_{1}=$ Harga jual atau biaya produksi setelah perubahan

$\mathrm{Y}_{0}=$ Harga jual atau biaya produksi sebelum perubahan

$\mathrm{Y}=$ Rata-rata perubahan harga jual atau biaya produksi

Pengukuran pendapata dapat dihitung dari selisih antara penerimaan dengan semua biaya produksi. Pengukuran produktivitas dapat dihitung dari unit yang diproduksi dengan masukan yang digunakan. Secara matematis dapat dirumuskan :

Produktivitas $=\frac{\text { Unit yang diproduksi }(\mathrm{kg})}{\text { Masukan yang digunakan }(\mathrm{HOK})}$

$\mathrm{Pd}=\mathrm{TR}-\mathrm{TC}=\left(\mathrm{Y} \cdot \mathrm{P}_{\mathrm{y}}\right)-\left(\sum \mathrm{X}_{\mathrm{i}} \cdot \mathrm{Px}_{\mathrm{i}}+\mathrm{BTT}\right)$

Keterangan :

$\mathrm{Pd}=$ Pendapatan

$\mathrm{TR}=$ Penerimaan Total

$\mathrm{TC}=$ Biaya total

$\mathrm{Y}=$ Hasil produksi $(\mathrm{kg})$

Py $=$ Harga hasil produksi $(\mathrm{Rp})$

$\mathrm{Xi}=$ Faktor produksi variabel ke-I $(1,2,3,4, \mathrm{n})$

Pxi $=$ Harga faktor produksi variabel ke-I (Rp/satuan)
BTT $=$ Biaya tetap total

\section{HASIL DAN PEMBAHASAN}

\section{Budidaya Ikan Patin di CV XYZ}

Kegiatan budidaya patin dilakukan dua kali dalam satu tahun. Budidaya ikan patin di CV XYZ meliputi kegiatan persiapan kolam, penebaran benih, pemberian pakan dan vitamin, dan panen. Pada saat persiapan kolam kegiatan yang dilakukan yaitu pengeringan kolam dengan menyedot air kolam menggunakan Dongfeng 1110. Lumpur yang berada di dasar kolam di bersihkan untuk kemudian kolam akan di berikan kapur untuk menetralkan $\mathrm{pH}$ tanah serta membunuh ikan predator yang berada di dalam kolam. Proses persiapan kolam berlangsung selama kurang lebih 10 hari sampai kolam siap untuk ditebar benih ikan.

Kegiatan kedua yaitu penebaran benih ikan patin. benih ikan patin yang digunakan merupakan benih yang berumur 1 bulan dengan ukuran 2 inch. Benih ikan patin diperoleh CV XYZ dari Kota Metro atau di Pasar 16C. Sebelum benih ikan patin di tebar, sekeliling kolam di pagar agar tidak ada hama yang masuk. Penebaran benih ikan patin di CV XYZ biasanya dilakukan di pagi hari. Setelah penebaran benih, pemberian pakan dilakukan 2 hari setelah tebar.

Pemberian pakan ikan patin di CV XYZ dilakukan tiga kali dalam satu hari. Pakan untuk ikan yang berusia 1-1,5 bulan diberi pakan pabrik seperti PF 1000, PF 781, PF 781-1, PF 781-2, PF 781-2SP. Setelah ikan berusia lebih dari 1,5 bulan akan diberi pakan buatan dengan komposisi bekatul 42,37 persen, ikan asin 16,42 persen, roti bekas 31,21 persen, dan bungkil sawit 10 persen. Pemberian pakan buatan dengan komposisi tersebut berdasarkan kebutuhan pakan per kolam. Vitamin dan obat-obatan yang digunakan bermacam-macam diantaranya viterna, indroflox, tetes tebu, dan nasa.

Setelah ikan berusia 6 bulan dengan bobot 300 gram, maka ikan sudah siap untuk dipanen. Kegiatan panen ini biasanya dilakukan pada saat pedagang datang untuk membeli ikan patin. Panen ikan dilakukan menggunakan jaring, ikan dibawa ke sudut kolam untuk memudahkan pekerja saat memindahkan ikan ke keranjang. Ikan yang dikumpulkan dalam jaring kemudian diangkat menggunakan keranjang untuk kemudian ditimbang 


\section{Analisis Finansial Usaha Budidaya Ikan Patin}

Penilaian keragaan usaha dari aspek finansial budidaya ikan patin akan dihitung pada saat tingkat suku bunga sebesar 12 persen. Tahun awal pada penelitian ini yaitu tahun 2012, karena pada tahun tersebut usaha budidaya ikan patin ini mulai dilaksanakan. Biaya investasi bangunan dan peralatan usaha budidaya ikan patin yaitu sebesar Rp335.334.000,60. Pada tahun 2012 CV XYZ memiliki 23 kolam budidaya dengan luas $10 \mathrm{~m} \mathrm{x}$ $20 \mathrm{~m}$. Air yang digunakan untuk mengisi kolam berasal dari irigasi. Sistem pembayaran sewa alat berat tersebut yaitu dihitung per jam, dan proses pembuatan kolam dengan eksavator membutuhkan waktu 200 jam atau sekitar 20 hari.

Biaya produksi merupakan biaya yang dikeluarkan selama kegiatan budidaya ikan patin dalam satu musim. Biaya produksi dalam usaha budidaya ikan patin di CV XYZ ini meliputi biaya benih, biaya pakan dan vitamin, biaya tenaga kerja, biaya peralatan, dan biaya lain-lain yang dapat dilihat pada Tabel 2. Tabel 2 menunjukkan biaya benih ikan patin dari tahun 2012-2017 berbeda, hal tersebut dikarenakan harga beli benih per ekor meningkat. Biaya benih yang dikeluarkan dalam satu musim budidaya per kolam sebesar Rp 630.000, per 23 kolam sebesar Rp 14.000.000, dan per $1.000 \mathrm{~m}^{2}$ sebesar Rp 3.150.000.

Tenaga kerja yang digunakan dalam usaha budidaya ikan patin berasal dari tenaga kerja luar keluarga. Terdapat 10 orang tenaga kerja yang setiap harinya melakukan kegiatan budidaya seperti persiapan kolam, sanitasi, pembuatan pakan, pemberian pakan, hingga panen.

Tabel 1. Biaya investasi dalam usaha budidaya ikan patin di CV XYZ

\begin{tabular}{lccr}
\hline \multicolumn{1}{c}{ Uraian } & Unit & $\begin{array}{c}\text { UE } \\
\text { (th) }\end{array}$ & \multicolumn{1}{c}{ Total Biaya (Rp) } \\
\hline Kolam & 23 & 10 & $68.900 .000,00$ \\
Tiang lampu & 12 & 3 & $180.000,00$ \\
Lampu & 12 & 2 & $336.000,00$ \\
Kabel & 1 & 10 & $218.000,00$ \\
Mobil & 1 & 10 & $130.000 .000,00$ \\
Alkon & 1 & 10 & $3.500 .000,00$ \\
Selang & 6 & 5 & $7.200 .000,00$ \\
Drum & 12 & 10 & $2.160 .000,00$ \\
Dongfeng & 3 & 10 & $25.000 .000,00$ \\
Jaring & 1 & 3 & $2.500 .000,00$ \\
Cangkul & 5 & 2 & $450.000,00$ \\
Waring & 10 & 10 & $3.000 .000,00$ \\
Gudang & 3 & 10 & $45.000 .000,00$ \\
Timbangan & 3 & 10 & $1.900 .000,00$ \\
Rumah Jaga & 2 & 10 & 30.000 .000 \\
\hline Total Biaya & & & $335.344 .000,60$ \\
\hline
\end{tabular}

Tabel 2. Biaya produksi dalam usaha budidaya ikan patin di CV XYZ

\begin{tabular}{|c|c|c|c|}
\hline Keterangan & $\begin{array}{l}\text { Per Kolam } \\
\text { (Rp) }\end{array}$ & $\begin{array}{c}\text { Per } 23 \text { Kolam } \\
(\mathrm{Rp})\end{array}$ & $\begin{array}{c}\text { Per } 1.000 \mathrm{~m}^{2} \\
(\mathrm{Rp})\end{array}$ \\
\hline Benih & $630.000,00$ & $14.000 .000,00$ & $3.150 .000,00$ \\
\hline Pakan & $10.090 .631,25$ & $232.084 .518,75$ & $50.453 .156,25$ \\
\hline $\begin{array}{l}\text { Vitamin } \\
\text { \&obat }\end{array}$ & $467.250,00$ & $10.746 .750,00$ & $2.336 .250,00$ \\
\hline $\begin{array}{l}\text { Tenaga } \\
\text { kerja }\end{array}$ & $2.005 .500,00$ & $46.126 .500,00$ & $11.252 .500,00$ \\
\hline Peralatan & $381.086,96$ & $8.765 .000,00$ & $1.905 .434,00$ \\
\hline $\begin{array}{l}\text { Biaya } \\
\text { lain-lain }\end{array}$ & $647.363,30$ & $13.741 .952,08$ & $3.236 .816,50$ \\
\hline
\end{tabular}

Upah pembuatan pakan, pemberian pakan, dan panen adalah upah Borongan yaitu upah yang diberikan atas dasar satuan barang (tugas) yang harus dikerjakan. Upah pembuatan sebesar $\mathrm{Rp} 250,00 / \mathrm{kg}$, sedangkan upah pemberian pakan yaitu sebesar Rp100,00/kg dan upah saat sebesar $\mathrm{Rp} 250,00 / \mathrm{kg}$. Biaya lainnya yang dikeluarkan dalam usaha budidaya ikan patin meliputi pajak, listrik, bahan bakar kendaraan, irigasi, bahan bakar mesin, dan sewa lahan. Biaya produksi yang dikeluarkan dalam usaha budidaya ikan patin dapat dilihat pada Tabel 2 .

Tabel 3 menunjukkan bahwa tahun 2012 biaya operasional dalam usaha budidaya ikan patin cukup besar. Hal tersebut dikarenakan pada saat tahun pertama usaha tersebut berjalan perusahaan mengeluarkan biaya investasi seperti peralatan budidaya ikan patin. Tahun 2012 perusahaan juga mengeluarkan biaya untuk membuat kolam dengan menyewa eksavator.

\section{Penilaian Kriteria Investasi}

Analisis finansial usaha budidaya ikan patin di CV $\mathrm{XYZ}$ yaitu analisis finansial per kolam, 23 kolam. dan per $1.000 \mathrm{~m}^{2}$ dapat dilihat pada Tabel 4 .

Perhitungan NPV untuk usaha budidaya ikan patin per kolam, per 23 kolam, dan per $1.000 \mathrm{~m}^{2}$ menggunakan Compounding Factor dan Discount Factor sebesar 12 persen diperoleh nilai NPV lebih besar dari 0 sehingga analisis usaha budidaya ikan patin layak untuk dijalankan.

Perhitungan analisis finansial usaha budidaya ikan patin di CV XYZ diperoleh nilai Net $\mathrm{B} / \mathrm{C}>1$. Artinya, setiap Rp1,00 biaya bersih yang telah dikeluarkan pada usaha budidaya ikan patin akan menghasilkan penerimaan bersih sebesar lebih dari $\mathrm{Rp} 1,00$. Oleh karena itu usaha budidaya ikan patin di CV XYZ layak untuk dijalankan. 
Tabel 3. Total biaya operasional ikan patin di CV XYZ tahun 2012-2017

\begin{tabular}{cccr}
\hline \multirow{2}{*}{ Tahun } & \multicolumn{3}{c}{ Total Biaya Produksi } \\
\cline { 2 - 4 } & Per Kolam & Per 23 Kolam & Per $1.000 \mathrm{~m}^{2}$ \\
\hline 2012 & $59.970 .092,38$ & $661.298 .720,83$ & $299.850 .461,88$ \\
2013 & $14.221 .831,51$ & $325.954 .720,83$ & $71.109 .157,53$ \\
2014 & $14.178 .896,72$ & $325.303 .220,83$ & $70.894 .483,62$ \\
2015 & $15.520 .201,07$ & $328.397 .220,83$ & $77.601 .005,36$ \\
2016 & $14.241 .396,72$ & $326.740 .720,83$ & $71.206 .983,62$ \\
2017 & $14.752 .266,29$ & $338.154 .720,83$ & $73.761 .331,45$ \\
2018 & $15.602 .266,29$ & $330.620 .720,83$ & $78.011 .331,45$ \\
2019 & $14.221 .831,51$ & $325.954 .720,83$ & $71.109 .157,53$ \\
2020 & $14.241 .396,72$ & $326.740 .720,83$ & $71.206 .983,62$ \\
2021 & $15.582 .701,07$ & $329.834 .720,83$ & $77.913 .505,36$ \\
\hline
\end{tabular}

Usaha budidaya ikan patin berdasarkan kriteria IRR per kolam, per 23 kolam, dan per $1.000 \mathrm{~m}^{2}$ didapatkan masing-masing nilai 13,06 persen, 75,89 persen, dan 13,06 persen. Artinya sampai pada tingkat suku bunga dibawah 13,06 persen, 75,89 persen, dan 13,06 persen usaha budidaya ikan patin layak dan menguntungkan. .

Hasil perhitungan waktu pengembalian investasi dalam usaha budidaya ikan patin per kolam, per 23 kolam, dan per $1.000 \mathrm{~m}^{2}$ di CV XYZ pada saat tingkat suku bunga 12 persen berbeda. Periode pengembalian investasi dalam skala kecil (per kolam) menunjukkan bahwa periode pengembalian investasi 9. Sehingga dapat dikatakan bahwa usaha dalam skala kecil (per kolam) menguntungkan untuk dijalankan. Namun, semakin banyak kolam untuk budidaya ikan patin yang dimiliki perusahaan maka akan mempercepat periode pengembalian investasi sehingga usaha ini menguntungkan dan layak untuk dijalankan

Hasil perhitungan analisis finansial usaha budidaya ikan patin di CV XYZ diperoleh nilai Gross B/C $>1$. Artinya, setiap Rp1,00 biaya yang dikeluarkan akan menghasilkan penerimaan sebesar lebih dari Rp1,00 untuk usaha budidaya ikan patin. Berdasarkan hasil tersebut Gross B/C lebih besar dari 1, sehingga usaha budidaya ikan patin di CV XYZ layak untuk dijalankan.

Tabel 4. Perhitungan analisis finansial usaha budidaya ikan patin di CV XYZ

\begin{tabular}{lrrr}
\hline Kriteria & \multicolumn{1}{c}{ Per kolam } & \multicolumn{1}{c}{ 23 kolam } & \multicolumn{1}{c}{ Per $1.000 \mathrm{~m}^{2}$} \\
\hline IRR & $14,40 \%$ & $76,30 \%$ & $14,40 \%$ \\
NPV & $10.990 .216,80$ & $2.081 .664 .245,25$ & $54.951 .084,01$ \\
PP & 9,91 & 4,77 & 7,41 \\
Gross & 1,04 & 1,39 & 1,04 \\
B/C & & & \\
Net & 1,12 & 5,46 & 1,12 \\
B/C & & & \\
\hline
\end{tabular}

\section{Analisis Sensitivitas}

Analisis sensitivitas digunakan bertujuan untuk melihat kepekaan dari analisis NPV, IRR, Net B/C, Gross B/C, dan Payback period terhadap perubahan-perubahan pada dasar perhitungan penerimaan dan biaya produksi. Perubahanperubahan pada usaha budidaya ikan patin di CV XYZ yang terjadi yaitu pada harga jual dan produksi ikan patin.

Hasil analisis sensitivitas penurunan harga jual terhadap usaha budidaya ikan patin di CV XYZ terlihat bahwa pada tingkat suku bunga 12 persen dengan penurunan harga jual sebesar 9,37 persen, penurunan produksi 25 persen, dan kenaikan biaya produksi 3,39 persen masing-masing kriteria mengalami perubahan. Analisis sensitivitas saat harga jual turun 9,37 persen dan penurunan produksi 25 persen menunjukkan bahwa usaha budidaya ikan patin cenderung sensitif terdahap perubahan harga jual. Hal tersebut ditunjukkan dengan laju kepekaan dari kriteria investasi NPV, IRR, dan Net B/C memiliki nilai lebih besar dari satu. Analisis sensitivitas pada saat biaya produksi naik sebesar 3,39 persen menunjukkan bahwa usaha budidaya ikan patin cenderung tidak sensitif terhadap perubahan biaya produksi. Hal tersebut ditunjukkan dengan nilai NPV, IRR, Net B/C, dan Gross B/C bernilai lebih kecil dari satu.

Diketahui bahwa harga jual ikan patin segar ditingkat produsen cenderung normal yaitu Rp15.000/kg. Pada penelitan ini diketahui umur proyek adalah 10 tahun dan usaha budidaya ikan patin sudah berjalan selama 8 tahun. Penentuan biaya dan produksi di tahun yang akan datang yaitu menggunakan asumsi bahwa biaya dan produksi ikan patin cenderung tidak jauh berbeda. Sehingga penentuan biaya dan produksi ikan patin dapat dilihat dari tahun 2018 dan diasumsikan sama. Produksi ikan patin tahun 2014 dan tahun 2015 mengalami penurunan sebesar 25 persen yang diakibatkan oleh serangan penyakit.

Penurunan produksi tersebut berdampak pada penurunan penerimaan yang diperoleh CV XYZ. Setelah mengetahui cara menangani serangan penyakit, produksi ikan patin kembali meningkat pada tahun 2016. Harga jual ikan patin di lokasi penelitian berkisar antara Rp14.000 sampai Rp16.000 per kilogram. Produksi dan penerimaan ikan patin di CV XYZ dapat dilihat pada Tabel 5. 
Jurnal Ilmu Ilmu Agribisnis: Journal of Agribusiness Science, 9(1), Februari 2021

Tabel 5. Produksi dan penerimaan dalam usaha budidaya ikan patin di CV XYZ

\begin{tabular}{|c|c|c|c|c|c|c|c|}
\hline \multirow{2}{*}{ Tahun } & \multicolumn{2}{|c|}{$\begin{array}{l}\text { Produksi per kolam } \\
\text { (kg) }\end{array}$} & \multirow{2}{*}{ Penerimaan (Rp) } & \multirow{2}{*}{$\begin{array}{l}\text { Produksi } 23 \\
\text { kolam (kg) }\end{array}$} & \multirow{2}{*}{ Penerimaan (Rp) } & \multirow{2}{*}{$\begin{array}{l}\text { Produksi } \\
\text { per } 1.000 \\
\mathrm{~m}^{2}(\mathrm{~kg})\end{array}$} & \multirow{2}{*}{ Penerimaan (Rp) } \\
\hline & MT-1 & MT-2 & & & & & \\
\hline 2012 & 653,00 & 490,00 & $17.145 .000,00$ & $30.000,00$ & $450.000 .000,00$ & $5.715,00$ & $85.725 .000,00$ \\
\hline 2013 & 870,00 & 652,50 & $22.837 .500,00$ & $35.000,00$ & $525.000 .000,00$ & $7.612,50$ & $114.187 .500,00$ \\
\hline 2014 & 652,50 & 489,38 & $17.128 .125,00$ & $26.250,00$ & $393.750 .000,00$ & $5.709,38$ & $85.640 .625,00$ \\
\hline 2015 & 652,50 & 489,38 & $17.128 .125,00$ & $26.250,00$ & $393.750 .000,00$ & $5.709,38$ & $85.640 .625,00$ \\
\hline 2016 & $1.000,00$ & 750,00 & $26.250 .000,00$ & $40.250,00$ & $603.750 .000,00$ & $8.750,00$ & $131.250 .000,00$ \\
\hline 2017 & $1.000,00$ & 750,00 & $26.250 .000,00$ & $40.250,00$ & $603.750 .000,00$ & $8.750,00$ & $131.250 .000,00$ \\
\hline 2018 & $1.000,00$ & 750,00 & $26.250 .000,00$ & $40.250,00$ & $603.750 .000,00$ & $8.750,00$ & $131.250 .000,00$ \\
\hline 2019 & $1.000,00$ & 750,00 & $26.250 .000,00$ & $40.250,00$ & $603.750 .000,00$ & $8.750,00$ & $131.250 .000,00$ \\
\hline 2020 & $1.000,00$ & 750,00 & $26.250 .000,00$ & $40.250,00$ & $603.750 .000,00$ & $8.750,00$ & $131.250 .000,00$ \\
\hline $2021 *$ & $1.000,00$ & 750,00 & $35.014 .637,68$ & $40.250,00$ & $805.336 .666,67$ & $8.750,00$ & $175.073 .188,41$ \\
\hline
\end{tabular}

Berdasarkan pada Tabel 5 diketahui bahwa penerimaan usaha budidaya ikan patin tahun 2021 meningkat. Hal tersebut dikarenakan pada tahun 2021 terdapat penerimaan yang diperoleh dari nilai sisa peralatan seperti kolam, mobil pick up, tiang lampu, jaring panen, gudang bahan baku pakan, gudang bahan bakar, gudang penyimpanan pakan, timbangan $10 \mathrm{~kg}$, timbangan $100 \mathrm{~kg}$, rumah penjaga depan dan rumah penjaga belakang. Penerimaan per kolam sebesar Rp 8.764.637,68, per 23 kolam sebesar Rp 201.586.666,67 dan per $1.000 \mathrm{~m}^{2}$ sebesar $\mathrm{Rp}$ 43.823.188,41.

\section{Produktivitas}

Berikut ini merupakan perhitungan produktivitas dalam usaha budidaya ikan patin meliputi per kolam, 23 kolam. dan per $1.000 \mathrm{~m}^{2}$ dapat dilihat pada Tabel 6. Produktivitas budidaya ikan patin per kolam dengan luas kolam $200 \mathrm{~m}^{2}$ sebesar 1.000 $\mathrm{kg}$ dan $750 \mathrm{~kg}$. Artinya dengan ukuran kolam 200 $\mathrm{m}^{2}$ perusahaan mampu menghasilkan $1.000 \mathrm{~kg}$ dan $750 \mathrm{~kg}$ ikan patin segar. Produktivitas budidaya ikan patin per hektar masing-masing sebesar $50.000 \mathrm{~kg}$ dan $37.500 \mathrm{~kg}$. Artinya, dengan 1 ha luas lahan budidaya ikan patin dapat menghasilkan ikan patin segar sebesar $50.000 \mathrm{~kg}$ dan $37.500 \mathrm{~kg}$. Produktivitas budidaya ikan patin berdasarkan tenaga kerja masing-masing sebesar $63,58 \mathrm{~kg} / \mathrm{HOK}$ dan $58,04 \mathrm{~kg} / \mathrm{HOK}$.

Tabel 6. Produktivitas dalam usaha budidaya ikan patin di CV XYZ

\begin{tabular}{llrr}
\hline Keterangan & Satuan & \multicolumn{1}{c}{ MT-1 } & \multicolumn{1}{c}{ MT2 } \\
\hline $\begin{array}{l}\text { Produktivitas } \\
\text { per kolam }\end{array}$ & $\mathrm{Kg}$ & $1.000,00$ & 750,00 \\
$\begin{array}{l}\text { Produktivitas } \\
\text { per ha }\end{array}$ & $\mathrm{kg} / \mathrm{ha}$ & $50.000,00$ & $37.500,00$ \\
$\begin{array}{l}\text { Produktivitas } \\
\text { per HOK }\end{array}$ & $\mathrm{Kg} / \mathrm{HOK}$ & 63,58 & 58,04 \\
\hline
\end{tabular}

Artinya setiap HOK mampu menghasilkan produksi ikan patin sebesar $60,58 \mathrm{~kg}$ dan $58,04 \mathrm{~kg}$ setiap musimnya. Dengan demikian produktivitas dalam usaha budidaya ikan patin di CV XYZ ini sudah cukup baik.

\section{Pendapatan}

Pendapatan yang diperoleh CV XYZ yaitu pendapatan atas biaya tunai dan pendapatan atas biaya total. Berdasarkan pengukuran pendapatan per kolam, 23 kolam, dan per $1.000 \mathrm{~m}^{2}$ diperoleh hasil yang bernilai positif yang berarti bahwa usaha budidaya ikan patin ini menguntungkan. Semakin banyak jumlah kolam yang digunakan untuk budidaya ikan patin maka semakin besar pendapatan yang diperoleh perusahaan. Perhitungan pendapatan dan nilai R/C Ratio dapat dilihat pada Tabel 7.

Pengukuran R/C Ratio dalam usaha budidaya ikan patin di CV XYZ dihitung berdasarkan per kolam, 23 kolam, dan per $1.000 \mathrm{~m}^{2}$ dapat dilihat pada Tabel 7. Berdasarkan Tabel 7 diperoleh bahwa nilai $\mathrm{R} / \mathrm{C}$ Ratio masing-masing kategori sama. Nilai R/C Ratio atas biaya tunai dan biaya total tiap musim lebih besar dari 1, hal ini berarti bahwa usaha budidaya ikan patin di CV XYZ menguntungkan dan layak untuk dijalankan.

\section{KESIMPULAN}

Usaha budiaya ikan patin di CV XYZ dari aspek kelayakan finansial berdasarkan beberapa kriteria investasi menunjukkan bahwa usaha budidaya ini menguntungkan dan layak untuk dilaksanakan. Serta dari aspek produksi berdasarkan pengukuran produktivitas dan pendapatan menunjukkan bahwa usaha budidaya ini menguntungkan. 
Jurnal Ilmu Ilmu Agribisnis: Journal of Agribusiness Science, 9(1), Februari 2021

Tabel 7. Pendapatan dan R/C Ratio dalam usaha budidaya ikan patin tahun 2018

\begin{tabular}{lrrrrrr}
\hline \multirow{2}{*}{ Keterangan } & \multicolumn{2}{c}{ Per Kolam } & \multicolumn{2}{c}{ Per 23 Kolam } & \multicolumn{2}{c}{ Per 1.000 $\mathrm{m}^{2}$} \\
\cline { 2 - 7 } & \multicolumn{1}{c}{ MT-1 } & \multicolumn{1}{c}{ MT-2 } & \multicolumn{1}{c}{ MT-1 } & \multicolumn{1}{c}{ MT-2 } & \multicolumn{1}{c}{ MT-1 } & \multicolumn{1}{c}{ MT-2 } \\
\hline Penerimaan & $16.000 .000,00$ & $12.000 .000,00$ & $368.000 .000,00$ & $276.000 .000,00$ & 80.000 .000 & 60.000 .000 \\
Biaya Tunai & $7.871 .556,65$ & $6.090 .787,90$ & $181.046 .215,35$ & $140.088 .534,10$ & $39.357 .781,81$ & $30.408 .105,07$ \\
Biaya Diperhitungkan & $947.311,59$ & $947.311,59$ & $21.788 .166,67$ & $21.788 .166,67$ & $4.736 .557,97$ & $4.736 .557,97$ \\
Total Biaya & $8.818 .868,24$ & $7.038 .099,49$ & $202.834 .382,02$ & $161.876 .700,77$ & $44.094 .339,78$ & $35.144 .663,04$ \\
Pendapatan atas biaya & $8.128 .443,35$ & $5.909 .212,10$ & $186.953 .784,65$ & $135.911 .465,90$ & $40.642 .218,19$ & $29.591 .894,93$ \\
tunai & & & & & & \\
Pendapatan atas biaya & $8.181 .131,76$ & $4.961 .900,51$ & $165.165 .617,98$ & $114.123 .299,23$ & $35.905 .660,22$ & $24.855 .336,96$ \\
total & 2,03 & 1,97 & 2,03 & 1,97 & 2,03 & 1,97 \\
R/C atas biaya tunai & 1,81 & 1,71 & 1,81 & 1,71 & 1,81 & 1,71 \\
R/C atas biaya total & & & & & &
\end{tabular}

\section{DAFTAR PUSTAKA}

Alfizar A, Hasyim AI, dan Affandi MI. Analisis kelayakan finansial kelapa sawit di Kabupaten Lampung Tengah. Jurnal Ilmu Ilmu Agribisnis 5(3): 228-234. https:// jurnal.fp.unila.ac.id/index.php/JIA/article/vie w/1634. [9 Februari 2020].

Anwar MS, Hasyim AI, dan Affandi MI. 2018. Analisis kelayakan finansial usaha pembibitan lada di Desa Sukadana Baru Kecamatan Marga Tiga Kabupaten Lampung Timur. Jurnal Ilmu Ilmu Agribisnis 6(2) : 110-116. https://jurnal.fp.unila.ac.id

/index.php/JIA/article/view/2275. [9 Februari 2020].

Astanu DA, Ismono RH, dan Rosanti N. 2013. Analisis kelayakan finansial budidaya intensif tanaman pala di Kecamatan Gisting Kabupaten Tanggamus. Jurnal Ilmu Ilmu Agribisnis 1(3):218-225. https://jurnal.fp.unila.ac.id/index.php/JIA/artic le/view/576. [9 Februari 2020].

Badan Pusat Statistik Provinsi Lampung. 2018. Pertumbuhan Ekonomi Provinsi Lampung. Badan Pusat Statistik Provinsi Lampung. Lampung.

Badan Pusat Statistik. 2018. Provinsi Lampung dalam Angka Badan Pusat Statistik Provinsi Lampung. Bandar Lampung.

Canita PL, Haryono D, dan Kasymir E. 2017. Analisis pendapatan dan tingkat kesejahteraan rumah tangga petani pisang di Kecamatan Padang Cermin Kabupaten Pesawaran. Jurnal Ilmu Ilmu Agribisnis 5(7): 235-241. https://jurnal.fp.unila.ac.id/ index. php/JIA/article/view/1634. [29 Januari 2020].

Devy J, Hasyim I, dan Situmorang S. 2018. Analisis kelayakan finansial dan risiko usaha budidaya jamur tiram di Provinsi Lampung. Jurnal Ilmu Ilmu Agribisnis 6(4): 347-354. https://jurnal.fp.unila.ac.id/index.php/JIA/artic le/view/3050. [29 Januari 2020].
Fika M, Suwandari A, Hartadi R. 2016. Analisis kelayakan finansial dan kontribusi pendapatan terhadap pendapatan rumah tangga pembudidaya ikan Lele Dumbo. Agritop Jurnal Ilmu-Ilmu Pertanian 14(2): 199-207. http://jurnal.unmuhjember.ac.id/index.php/AG RITROP/article/view/434/. [29 Maret 2019].

Harianto E. 2015. Kinerja produksi kepiting bakau Scylla serrata cangkang lunak pada metode pemotongan capit dan kaki jalan, popey, dan alami. Jurnal Ilmiah Universitas Batanghari Jambi 15(1) : 15-21. http://ji.unbari.ac.id/ index.php/ilmiah/article/view/193/189. Maret 2019].

Mayasari D, Darwis, Hamid H. 2017. Analisis usaha pembesaran ikan gurami dan ikan patin di Kelurahan Rejosari Kecamatan Tenayan Raya Kota Pekanbaru Provinsi Riau. Jurnal Online Mahasiswa Fakultas Perikanan dan Ilmu Kelautan 4(2); 1-13.

https://webcache.googleusercontent.com/searc $\mathrm{h}$ ?q=cache:0GqvIBpgKAIJ:https://media.nelit i.com/media/publications/203107none.pdf $+\& \mathrm{~cd}=1 \& \mathrm{hl}=\mathrm{en} \& \mathrm{ct}=\mathrm{clnk} \& \mathrm{gl}=\mathrm{id} \& \mathrm{cli}$ ent=firefox-b-d. [29 Maret 2019].

Ngamel YA, Lubis E, Pane AB, dan Solihin I. 2013. Kinerja operasional Pelabuhan Perikanan Nusantara Tual. Jurnal Teknologi Perikanan dan Kelautan 4(2) : 155-172. http://journal.ipb.ac.id/index.php/jtpk/article/v iew/15926/11798. [29 Maret 2019].

Pasaribu AM. 2012. Perencanaan \& Evaluasi Proyek Agribisnis (Konsep dan Aplikasi). Lily Publisher. Yogyakarta.

Prabowo BB, Zakaria WA, dan Endaryanto T. 2018. Analisis kelayakan finansial unit usaha jasa mesin penanam padi di Kecamatan Seputih Raman Kabupaten Lampung Tengah. Jurnal Ilmu Ilmu Agribisnis 6 (4): 400-406. http://jurnal.fp.unila.ac.id/index.php/JIA/articl e/view/3060. Februari 2020].

Prasetya H dan Lukiastuti F. 2009. Manajemen Operasi. Media Pressindo. Yogyakarta. 
Jurnal Ilmu Ilmu Agribisnis: Journal of Agribusiness Science, 9(1), Februari 2021

Rahim A. dan Hastuti DRD. 2008. Ekonomika Pertanian. Penebar Swayada. Jakarta.

Salsabilla S, Haryono D, Syarief YA. 2019. Analisis pendapatan dan nilai tambah agroindustri keripik pisang di Desa Sungai Langka Kecamatan Gedong Tataan Kabupaten Pesawaran. Jurnal Ilmu Ilmu Agribisnis 7(1):68-74. https://jurnal.fp.unila.ac.id/index.php/JIA/artic le/view/333. [9 Februari 2020].

Shafira F, Lestari DAH, dan Affandi MI. 2018. Keragaan agroindustri tahu kulit di Kelurahan Gunung Sulah Kecamatan Way Halim Kota Bandar Lampung. Jurnal Ilmu Ilmu Agribisnis 6(3):279-287. https://jurnal .fp.unila.ac.id/index article/view/3025. [29 Januari 2020].

Sazmi RM, Haryono D, dan Suryani A. 2017. Analisis pendapatan dan efisiensi pemasaran ikan patin di Kecamatan Seputih Raman Kabupaten Lampung Tengah. Jurnal Ilmu Ilmu Agribisnis 6(2):133-141. http://jurnal.fp.unila.ac.id/index.php/JIA /article/view/2778. [9 Oktober 2019].

Sunarya BSC, Abidin A, dan Kalsum U. 2016. Analisis finansial usaha ternak ayam probiotik : Studi Kasus : KPA Berkat Usaha Bersama Kota Metro. Jurnal Ilmu Ilmu Agribisnis 4(1):15-23.

http://jurnal.fp.unila.ac.id/index.php/JIA/articl e/view/1210. [9 Februari 2020].

Susanti S, Lestari DAH., dan Kasymir E. 2017. Sistem agribisnis ikan patin (Pangasius sp) kelompok budidaya ikan sekar mina di Kawasan Minapolitan Patin Kecamatan Kota Gajah Lampung Tengah. Jurnal Ilmu Ilmu Agribisnis 5(2):116-123. http://jurnal.fp.unila.ac.id/index.php/JIA/articl e/view/1648. [29 Maret 2019]. 